\title{
The optimal interaction between a hedge fund manager and investor.
}

DOI:

10.1080/1350486X.2018.1506258

\section{Document Version}

Accepted author manuscript

Link to publication record in Manchester Research Explorer

\section{Citation for published version (APA):}

Ramirez, H. E., Duck, P., Johnson, P., \& Howell, S. (2018). The optimal interaction between a hedge fund manager and investor. Applied Mathematical Finance. https://doi.org/10.1080/1350486X.2018.1506258

\section{Published in:}

Applied Mathematical Finance

\section{Citing this paper}

Please note that where the full-text provided on Manchester Research Explorer is the Author Accepted Manuscript or Proof version this may differ from the final Published version. If citing, it is advised that you check and use the publisher's definitive version.

\section{General rights}

Copyright and moral rights for the publications made accessible in the Research Explorer are retained by the authors and/or other copyright owners and it is a condition of accessing publications that users recognise and abide by the legal requirements associated with these rights.

\section{Takedown policy}

If you believe that this document breaches copyright please refer to the University of Manchester's Takedown Procedures [http://man.ac.uk/04Y6Bo] or contact uml.scholarlycommunications@manchester.ac.uk providing relevant details, so we can investigate your claim.

\section{OPEN ACCESS}


[2000]49L20, 49L25, 49M37, 65K10, 65N06, 65M06, 90C39, 91G10, 91G60, 91G80, 93E20, 93E25. JEL:C32, C41, C44, C54, C61, C63, C65, G11.

Hedge funds, Stochastic control, Portfolio optimization, Strategic decisions, Finite differences, Investor's participation 


\title{
The optimal interaction between a hedge fund manager and investor.
}

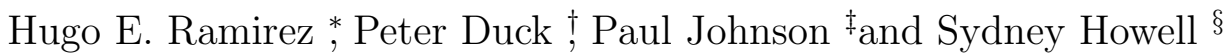

\begin{abstract}
Over a hedge fund comprising one risky asset and one risk-less bond, we model a manager's wealth and the corresponding investor's wealth. Then we maximise the expected utility of wealth of the manager, by controlling the percentage invested in the risky asset, and obtain the utility of wealth of the investor under the decisions made by the manager. We use stochastic control techniques to derive partial differential equations (PDEs) for each agent and numerically obtain their corresponding viscosity solutions. We then propose a new hedge fund contract where the investor has the option to reinvest in the fund, to do so we model a strategic game where the manager's decision is how allocate the money between the two investments and the investor's decision is to add money to the fund if he perceives a benefit. The results show that the investor is inflowing money to keep the fund open because it is more beneficial, and we found that in some cases this strategy does not make both agents profit creating a reverse effect for the investor.
\end{abstract}

\section{Introduction}

Given the boom in hedge funds and the increasing amounts of money that are managed by this industry, we present an academic version of the investors view of hedge funds. This work is motivated by the fact that investors have to pay huge amounts of money to the managers and we explore the actual benefits of these type of investments.

Building on the model structured in the paper on hedge fund management by ?, the fund value consists of one risky and one riskless investment. The manager controls the allocation between these two investments and the fund has normally-distributed log returns, that is the manager is allowed to dynamically alter the allocation proportion in the risky investment. The manager's compensation depends on three factors: he owns a fraction of the fund, typically about $10 \%$. On the remaining fraction of the fund he charges an

\footnotetext{
*Faculty of Economics, Universidad del Rosario. Address: Calle 12C No. 6-25 Bogota, COL. Email: hugoedu.ramirez@urosario.edu.co

†School of Mathematics, The University of Manchester, Manchester, U.K. Email: duck@maths.manchester.ac.uk

$\ddagger$ School of Mathematics, The University of Manchester, Manchester, U.K. Email: pjohnson2@maths.manchester.ac.uk

$\S$ Business School, The University of Manchester, Manchester, U.K. Email: sydney.howell@manchester.ac.uk
} 
annual fee as a percentage (less than $5 \%$ ), and he earns an incentive fee over the excess of a prescribed goal or high-water mark (i.e. about $20 \%$ of the excess of the fund value over the high-water mark). The high-water mark is adjusted to the manager's performance in the sense that, if at the payment time (i.e. at the end of the contract or payment period) the fund's value surpasses the high-water mark then it must be updated to a new goal (or high-water mark) for the next period.

Furthermore the fund may be closed by the manager (called endogenous closure) or by the investor (called exogenous closure). In the former the manager chooses to shut down the fund, when he identifies an outside opportunity that gives him more earnings. In the exogenous closure the investor closes the fund because of poor performance. That is, if the fund falls below some established liquidation boundary (corresponding in this paper to half of the high-water mark), the investor chooses to close the fund. In our setting the incentive fee is modeled as an European Call option, the endogenous closure generates a free-boundary problem which we evaluate as an American option and the reseting of the high-water mark is treated as a look-back option, furthermore the exogenous closure induces a discontinuity in the value function.

Next, we notice that the reward scheme for hedge funds is very high, so the natural questioning is if the investor is receiving a positive return after paying manager's fees, and how high should the manager's excess of return, known as the alpha, have to be in order to cover his own fees? After exploring the relevant literature, we find that: ? explore the incentive fee effects on the riskiness of manager and investors, and ? model investor's decisions to redeem capital from a hedge fund as a real option and value the cost of lockups and notice periods for a risk-averse investor, but the literature we found did not solve our questioning.

During 2014 there was a storm of news related to hedge funds in media outlets such as Bloomberg and MarketWatch, exposing some of our same questionings about the investor's actual return. For instance? claims that some hedge funds actually generate alpha, which results in positive returns for the investor, but funds having out performance are rare and those that keep outperforming year after year are even rarer. He states that when there were few hedge funds the concentration of talent was there, but currently people invest in hedge funds for an additional social value such as status and relationships with other wealthy persons, because it gives them the feeling to belong to some elite. Moreover, ? exposes a bet between Warren Buffett and the hedge fund firm Protege: Buffett's side consists of buying $\$ 320,000$ in bonds on the Standard \& Poor's 500 Index S\&PX (worth $\$ 1,000,000$ in ten years), starting from January 2008 and then waiting until the payoff date. The hedge fund could do whatever investment hedge funds do. In early 2014 it was reported that the hedge fund approach was up $12.5 \%$ after fees, while Buffett's index fund was up $43.8 \%$, the difference is mainly because of the fees or charges, $0.05 \%$ of the index fund against the high reward scheme of hedge fund managers. Later in 2015, Ted Seides (Co-founder of Protege) realised of his lost against Warren Buffet and left the fund. This reinforces the need for research in investors profit.

Motivated by this uninvestigated area we propose an innovative model for an investor in hedge funds, which involves the management fees and closure conditions. Our model consists of describing the investor's wealth in the hedge fund subject to the allocation decisions of the manager. We solve it (numerically), and find that under our original assumptions the return on the risky asset must be very high in order to compensate for 
manager fees, at about $20 \%$ annually. We also find that, investors are seeing a profit mainly when the fund value is between closure and the high-water mark, which coincides with the region of higher risks decisions for the manager. However this results change with our assumptions about the parameters, since if we set the risk-free interest rate to zero, the manager has to improve his strategy to get the incentive fee and this has a positive effect on the investor, who now sees a profit if the fund has a return on the risky asset greater than $4 \%$ annually.

After exploring on the investor's wealth and because statistical evidence in ? suggests that high returns in hedge funds are rare, we decided that there are few arguments to invest in a hedge fund, other than diversifying the fund or for social reasons (such as status and networking). We propose a new and original model, creating a different type of contract where, after the hedge fund has started, the investor has the option to reinvest (or inflow money) at some specific period. Here we use a strategic game to model the interaction between the investor who decides whether to inflow money in the hedge fund or keep the money in his bank account, and the manager who chooses the optimal allocation to maximise his payment. We find that the investor is willing to inflow money into the hedge fund, even when it has a low rate of return. Among other results, we find that the manager changes his strategy and does not close the fund endogenously, instead of closing he is now betting on very risky positions to keep the fund open and get the inflow from the investor. We also notice the possibility of win-win strategies for manager and investor, which are only possible with collaboration.

Research on inflows/outflows on hedge funds is not uncommon. For example, ? find evidence that alpha-generating hedge funds are more likely to receive capital flows than the beta (a measure of volatility or systematic risk) only funds, although capital flows into alpha-generating hedge funds are not a trend-chasing behaviour. ? create a model with inflow/outflow and investor's liquidation, and stress that the manager has to generate very high alphas to compensate for his fees. In contrast, our model shows that even funds with low alphas are likely to receive investors' inflow.

The remainder of this paper is organised as follows: in section ?? we describe the hedge fund management model and check the conditions for obtaining a numerical solution. Section ?? shows the investor extension to the hedge fund problem and section ?? states the investor-manager problem as a strategic game between the value functions corresponding to the HJB PDEs and presents a numerical approximation to solve the problem. Section ?? gives some results and section ?? draws some conclusions.

\section{$2 \quad$ Hedge fund management model}

One of the most remarkable features of hedge funds is the manager's fee payment. The manager gets paid a management fee and an incentive fee whenever he surpasses a preestablished high-water mark, which causes a risk-seeking behaviour and changes the strategy of the manager. Then the returns of a hedge fund do not depend solely on the initial allocation or quantity of assets but also on a dynamic strategy.

As a first stage we adopt the ideas in ?. Let $X_{t}$ represent the fund value at a time $t$, which consists of one risky and one riskless investment (i.e. one asset and one bond). The manager controls the allocation between these two investments. The risky investment has 
a constant expected grow rate $\mu$ and volatility $\sigma$, and the riskless investment grows at a constant rate $r$.

The proportion allocated in the risky investment is denoted $p$ (short for $p(t, X)$ ) and the manager dynamically alters the value of $p$. We assume that the fund $X_{t}$ follows a log-normal distribution with dynamics

$$
d X_{t}=X_{t}(p \mu+(1-p) r) d t+X_{t} p \sigma d B_{t},
$$

where $B_{t}$ represents a standard Brownian motion.

To model the manager's wealth $f\left(X_{t}\right)$, we describe the means by which a hedge fund manager can earn money:

1. The manager owns a fraction of the fund, named $a$, typically about $10 \%$ of the fund (i.e. $a=0.1$ ).

2. The management fee is a percentage $b$ of the non-owned portion of the fund and is paid over the period of management (i.e. from 0 to $T$ ), that is $(1-a) b T X_{T}$ where $b=0.02$ corresponds to $2 \%$ per period. This fee is only paid at time $T$. If the fund is closed before $T$, the management fee will be prorated according to the actually managed time.

3. The manager also earns a performance based fee or incentive fee $c=20 \%$ of the excess of the fund value over a pre-established high-water mark $H$. So the manager earns the fee only when the fund value $X_{T}$ is greater than $H$.

Suppose that the fund continues until the terminal date $T$, then the manager's wealth is based on the fraction of the fund he owns, plus the management fee, plus the incentive fee whose behaviour corresponds to a European call option based on the high-water mark $H$, thus

$$
f\left(X_{T}\right)=a X_{T}+(1-a) b T X_{T}+(1-a) c\left(X_{T}-H\right)^{+} .
$$

A complication arises when the fund performs poorly, in which case the investor decides to close the fund (exogenous closure). The simplest approach is to have a lower boundary to liquidation $\Phi$ and we set this mark to half of the high-water mark (i.e. $\Phi=0.5 H$ ), so in the case of an early closure of the fund, the manager ends up with his personal investment plus the proportional management fee, that is

$$
f\left(X_{t}\right)=a X_{t}+t(1-a) b \Phi \quad \text { for } 0 \leq t<T
$$

where $t$ depends on the time when the fund reaches the lower boundary.

Furthermore, we assume the manager has some endogenous reason to shut down the fund. Examples of endogenous reasons are: going to work for another organisation, starting a new investment, or having low fund value. This type of closure converts the problem into an optimal stopping and control problem because the manager, at each instant of time, has to revise whether is better for him to close the fund or keep it open. We follow ?, who model the manager's outside opportunities using $L$ to represent an annual compensation rate, although in their model the compensation does not depend on the fund value, but on the ratio $\frac{X}{H}$. If the manager chooses to liquidate the fund at time $t$, he receives

$$
f\left(X_{t}\right)=a X_{t}+(1-a) b t X_{t}+L(T-t) \quad \text { for } 0 \leq t<T
$$


So under the incentive of wining $L(T-t)$, the manager is willing to liquidate if he believes that the fund is going to give an incentive less than $L(T-t)$.

Then, the manager's wealth at terminal time is

$$
f\left(X_{T}\right)= \begin{cases}a X_{T}+(1-a) b T X_{T}+(1-a) c\left(X_{T}-H_{T}\right)^{+} & \text {If no closure events occurs. } \\ a X_{t}+(1-a) b t X_{t}+L(T-t) & \text { If an endogenous closure } \\ a X_{t}+(1-a) b t \Phi & \text { happen at time } t<T . \\ & \text { If an exogenous closure } \\ & \text { happen at time } t<T .\end{cases}
$$

and the manager's problem is to find the optimal portfolio allocation $p$ and stopping time $\tau$ that maximises his expected utility of wealth

$$
J\left(t, X_{t}=x\right)=\sup _{\tau \in \mathcal{T}}\left\{\sup _{p \in \mathcal{A}}\left\{\mathbb{E}^{t, x}\left[U\left(f\left(X_{\tau}\right)\right)\right]\right\}\right\}
$$

where $\mathcal{T}$ is the set of stopping times bounded by $T$ and $\mathcal{A}$ is the set of admissible controls. Moreover, the manager has a CRRA utility function with risk aversion parameter $\gamma$, namely

$$
U\left(f\left(X_{T}\right)\right)=\frac{f^{1-\gamma}\left(X_{T}\right)}{1-\gamma} .
$$

If more than one period is allowed, we have to reset the high-water mark each new period (i.e. year). This means that at each new period we update the high-water mark to the fund value, when the value of the fund exceeds the previous high-water mark, as a new incentive for the manager.

Our implementation of this problem differs from that in ?, since we state the problem as a continuous stochastic control problem (which has a unique viscosity solution) and solve it via finite differences, because this allows us to extend the model to more dimensions. Thus for the manager, we use stochastic control techniques and then state the corresponding Hamilton-Jacobi-Bellman (HJB) partial differential equation (PDE) maximising over all possible $p$ in a compact set, that is

$$
\begin{gathered}
\max \left\{-\frac{\partial J}{\partial t}-\sup _{p}\left\{\frac{1}{2} \sigma^{2} p^{2} X^{2} \frac{\partial^{2} J}{\partial X^{2}}+((r+(\mu-r) p) X) \frac{\partial J}{\partial X}\right\}, G-J\right\}=0, \\
J\left(T, X_{T}\right)=U\left(f\left(X_{T}\right)\right) .
\end{gathered}
$$

where $G$ is the utility of the outside opportunity, i.e.

$$
G=G(t, X)=U\left(a X_{t}+(1-a) b t X_{t}+L(T-t)\right) .
$$

On the other hand, ?'s approach is a discrete dynamic programming problem solved with a method similar to quadrature, for explanation of the quadrature method refer to ?.

Because of the special reward scheme and closure conditions we end up with a solution that is not smooth enough thus the need of the theory of viscosity solutions (which extends the stochastic control). We prove that this problem has a unique viscosity solution (in appendix ??), then we solve the HJB PDE numerically and check the appropriate conditions for numerical convergence (in appendix ??). 


\subsection{Computational approximation}

We solve this problem by using the Crank-Nicolson-PSOR scheme. As is known, the main difficulty of finite differences is finding appropriate boundary conditions, in this case at the minimum $\left(X_{\min }\right)$ and maximum $\left(X_{\max }\right)$ allowed values of the fund, which in our case are:

- When $X$ is small compared with the high-water mark, we expect the fund to be closed and hence no changes in its value during time (no changes in the fund for values of $X<\Phi)$, that is

$$
\left.\frac{\partial J}{\partial t}\right|_{X=X_{\min }}=0
$$

- When $X$ is large compared with the high-water mark we neglect the effect of the incentive fee, then we expect that the manager invest according to the Merton's optimal allocation strategy and hence

$$
\left.\frac{\partial J}{\partial t}\right|_{X=X_{\max }}=-\left(r+\frac{1}{2} \frac{(\mu-r)^{2}}{\sigma^{2} \gamma}\right)(1-\gamma) J
$$

Another boundary is the free boundary generated because of the endogenous closure, which is dealt as an American option.

\section{Investor in hedge funds}

In this section we explore the expected wealth of the fund's investors, or owners, when investing in a hedge fund administered by a manager who earns all the fees described in the previous section (we treat investors as a single entity henceforth we just use the investor). First remember that $J(t, X)$ represents the maximum expected terminal ${ }^{1}$ utility of wealth for a manager starting at time $t$ with an initial fund value $X$. In order to calculate the investor's utility of wealth, we recall that he owns the majority of the fund and hence his wealth is: the resulting wealth from the fund minus the manager's wealth (corresponding to the percentage of the fund owned by the manager, the management fee and the incentive fee), that is $X-f(X)$. Setting $\widehat{V}$ as the investor's value function (i.e. expected utility of wealth), we have that

$$
\widehat{V}\left(t, X_{t}=X\right)=\mathbb{E}^{t, X}\left[U_{I}\left(X_{T}-f\left(X_{T}\right)\right)\right]
$$

where $U_{I}$ represents the investor's utility of wealth, which in our case is a CRRA utility function with risk aversion parameter $\gamma_{I}$, and where $f\left(X_{T}\right)$ is as in (??). Since the value function $\widehat{V}$ for the investor depends on the same fund (i.e. variables) as that for the manager, and since portfolio decisions in the fund are made by the manager, i.e. the known values $p^{*}$, then our problem is no longer a stochastic control problem. Therefore

\footnotetext{
${ }^{1}$ By terminal we mean that the fund contract starts at time $t$ and finishes at, the final time, $T$.
} 


\begin{tabular}{cc|cc}
$T_{\max }$ & 1.0 & $H$ & 1.0 \\
$\Gamma_{\min }$ & -0.08 & $\Gamma_{\max }$ & 0.08 \\
$\mu$ & 0.0778 & $\sigma$ & 0.05 \\
$r$ & 0.0578 & $\gamma$ & 4 \\
$\gamma_{I}$ & 4 & $L$ & 0.018 \\
$a$ & 0.1 & $b$ & 0.02 \\
$c$ & 0.2 & $\mathfrak{p}$ & 2
\end{tabular}

Table 1: Investor in hedge funds parameter set.

to derive dynamics for the value function, we use Kolmogorov's backward equation (or in a more general sense the Feynman-Kac formula), resulting in the following PDE for the investor's wealth

$$
\begin{gathered}
\frac{\partial \widehat{V}}{\partial t}+\frac{1}{2} \sigma^{2} p^{* 2} X^{2} \frac{\partial^{2} \widehat{V}}{\partial X^{2}}+\left(r+(\mu-r) p^{*}\right) X \frac{\partial \widehat{V}}{\partial X}=0, \\
\widehat{V}(T, X)=U_{I}(X-f(X)),
\end{gathered}
$$

where $p^{*}=p^{*}(t, X)$ is the optimal allocation chose by the manager, and where equation (??) is the final condition.

Note that in this case we do not maximise over $p$, because we use the $p^{*}$ values obtained from the previous calculated decisions for the optimal manager's wealth problem.

As before, we use numerical techniques (Crank-Nicolson, but with LU decomposition) to solve the problem and next we show some motivational results for the problem in equations (??) and (??). We use, unless stated differently, the parameter set in table ?? and in the case of any changes in these parameters (specifically $\mu$ and $\sigma$ ), we adopt Merton's optimal allocation strategy $\mathfrak{p}=2$ as constant, which means that we change the parameters to keep the quotient $\mathfrak{p}=\frac{\mu-r}{\sigma^{2} \gamma}$ fixed, and in this way the manager's optimal position is not noticeably affected. Note also that this is also consistent with the fact that any increase in the expected return $\mu$ implies an increase in the volatility $\sigma$.

Remark 3.1. We do not attempt to calculate the investor's fund wealth from the data obtained in the manager's problem (i.e. by subtracting the inverse of the fund value) because, by using Jensen's inequality for concave functions and since $f\left(X_{t}\right)$ is the stochastic process for manager's wealth, we know that

$$
\mathbb{E}\left[U\left(f\left(X_{t}\right)\right)\right] \leq U\left(\mathbb{E}\left[f\left(X_{t}\right)\right]\right),
$$

and since for our utility functions we have increasing $U^{-1}$, then

$$
U^{-1}\left(\mathbb{E}\left[U\left(f\left(X_{t}\right)\right)\right]\right) \leq \mathbb{E}\left[f\left(X_{t}\right)\right]
$$

thus we cannot actually say that the inverse $U$ gives the manager's expected terminal wealth $f\left(X_{t}\right)$ which should be used to calculate the investor's wealth. Nevertheless, this inverse function valuation is useful and it is called the certainty equivalent. 


\subsection{Motivational results}

Next, we explore which option is best for the investor, if he is better to keep his money in a riskless investment (such as a bank account) in which case he earns a low but known constant interest rate $r$ (and pays no fees), or is it better to invest in a hedge fund where he expects his wealth to grow more than in the bank but with both increased risk and fees to pay. We also examine what if the investor would be able to invest in the same assets as the manager, in which case the best the investor can do is allocate following Merton's optimal strategy. One might expect that a reasonable result would be that the value of an investment in the hedge fund should be between the investor's riskless investment and the investor's allocating according Merton's optimal strategy, however we are able to demonstrate that this is not always the case.

In order to show the excess of the utility function, we take the difference between the value function $\hat{V}(t, X)$ and the equivalent of the investor entrusting his money in a riskless investment with constant interest rate $r$, the latter of which is given by

$$
\hat{V}_{R F}(t, X)=U_{I}\left((1-a) X e^{r(T-t)}\right)
$$

where the portion of the fund owned by the investor is $(1-a)$. We also take the difference compared to Merton's optimal strategy, which is given by (using Merton's solution for a investment with CRRA utility)

$$
\widehat{V}_{M O}(t, X)=\exp \left\{\left(r+\frac{(\mu-r)^{2}}{2 \sigma^{2} \gamma_{I}}\right)\left(1-\gamma_{I}\right)\left(T_{\max }-t\right)\right\} U_{I}((1-a) X) .
$$

In figure ?? we plot the differences $\hat{V}-\hat{V}_{R F}$ and $\hat{V}-\hat{V}_{M O}$, and we see that in neither case it is better to invest in the hedge fund, since the differences of the value functions are always negative. In this figure the effect of the fee payment above the high-water mark is noticeable beyond the mark $X=H=1$ seen as a decrease in the differences, because the investor has to pay more to the manager, which is seen as a loss. Under this parameter set, where the manager and investor have the same utility function, we can see that the manager's strategy is suboptimal for the investor and hence the investor would not invest in the hedge fund, because this gives a value function (for the investor) below the riskless investment.

The expected results are obtained if we use the whole fund (i.e. terminal value $U_{I}(X)$ ), when the manager and investor share the same CRRA utility function, the fund's wealth when administered by the manager behaves better than the riskless investment, but never better than Merton's optimal strategy (as expected).

Since with the original set of parameters (i.e. as in table ??) the hedge fund does not seem beneficial for the investor, and since the riskless investment (without a manager, more specifically without incentive fees) would yield greater profit, we pose the question: is the risky asset not giving enough return to compensate the payment due to manager fees? In order to answer this question, we increase the value of the expected return of the risky asset $\mu$ and compare the results again with the riskless investment. We also change the volatility of the risky asset accordingly to keep the value of $\mathfrak{p}$ constant (this resembles the statement that higher returns have higher risks or volatility) and table ?? shows the values used for this comparison. 


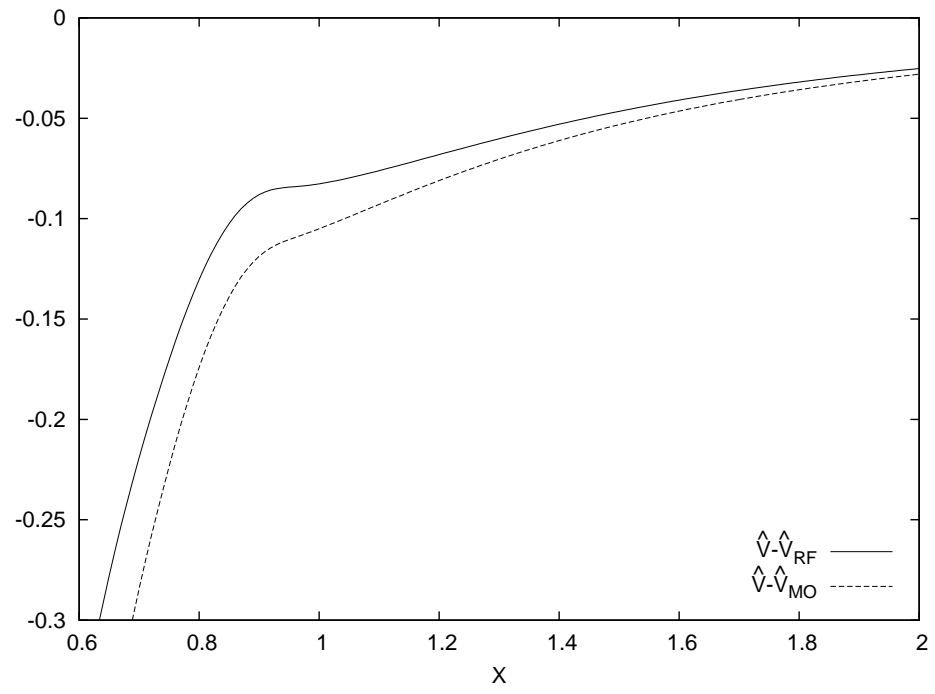

Figure 1: $\hat{V}-\hat{V}_{R F}$ represents the difference between the value function for the investor and his utility wealth by having the money in the riskless investment, $\hat{V}-\hat{V}_{M O}$ represents the difference between the value function for the investor and investing (for himself) the money with Merton's optimal strategy.

\begin{tabular}{c|c}
$\mu$ & $\sigma$ \\
\hline 0.0778 & 0.05 \\
\hline 0.1 & 0.07263 \\
\hline 0.15 & 0.10735 \\
\hline 0.2 & 0.133323 \\
\hline 0.25 & 0.155 \\
\hline 0.3 & 0.17399
\end{tabular}

Table 2: Different combinations for expected return of the risky asset and the corresponding volatility in order to preserve the ratio $\mathfrak{p}=2$. 


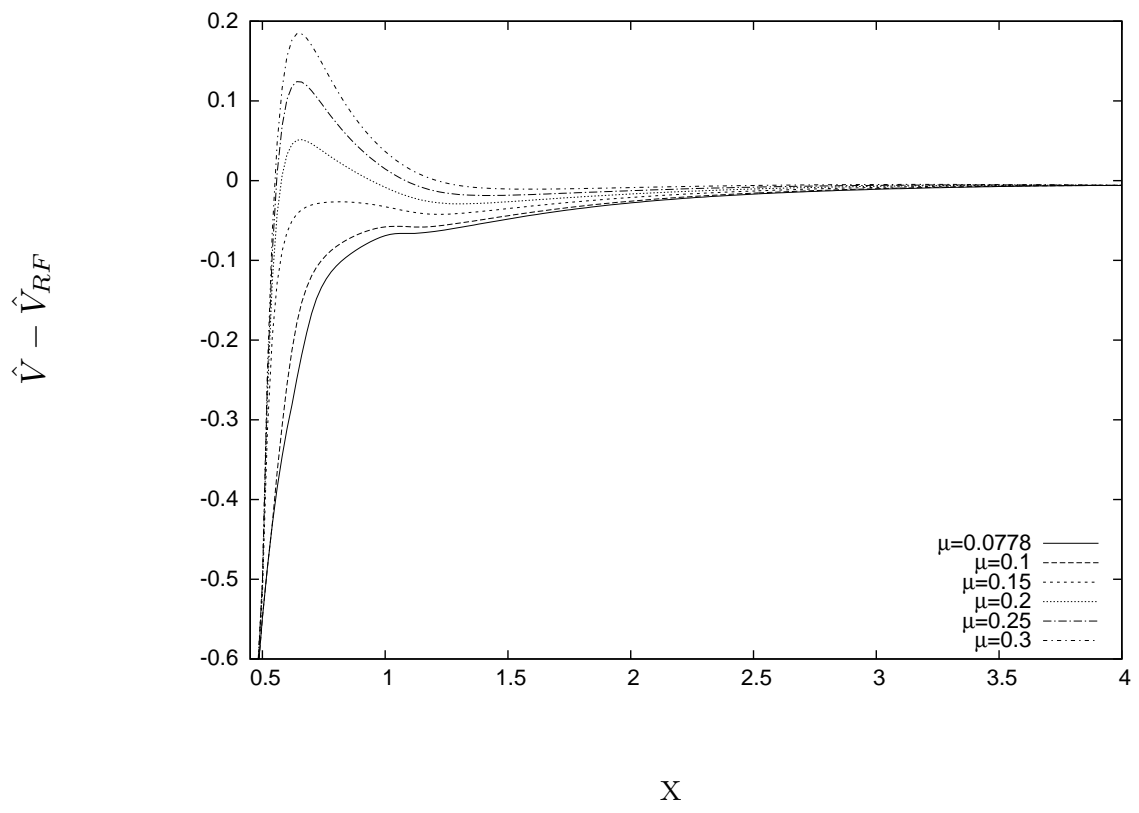

Figure 2: Plots of $\hat{V}-\hat{V}_{R F}$ functions, where we change the expected return of the opportunity (i.e. $\mu$ for risky investment) spotted by the manager, and proportionally we change the variance to preserve the ratio $\mathfrak{p}=2$.

In figure ?? we plot the difference $\hat{V}-\hat{V}_{R F}$. We see that the first of the differences where the investor receives some benefit is when $\mu=0.2$, and also that this benefit is only noticeable in a zone between the closure and the high-water mark. This means that the investor does not receive benefit unless the manager spots an asset (or combination of assets) that gives an expected return approximately greater than 0.2 , i.e. $20 \%$ annually, which agrees with ?.

We notice that for an investor to receive profit, represented as a increase in the value function, the manager must spot a very high return in the investment, and according to ? such out-performances are rare. Thus we examine another possible reason for the popularity hedge funds, and in this case we consider the risk perspective in the investor's utility $U_{I}$, i.e. changing the risk aversion parameter $\gamma_{I}$. Thus a combination of high returns $\mu$ and different perspective $\gamma_{I}$ is the best way to explain the popularity of hedge funds and in figure ?? we show the plots of the difference $\hat{V}-\hat{V}_{R F}$, where the expected return of the risky asset is $\mu=0.15$ (and volatility $\sigma=0.10735$ ), and we vary the investor's risk-aversion parameter $\gamma_{I}$. Note that with this value of $\mu$, and for $\gamma_{I} \leq 3$, the investor expects to receive some profit, and then he is be happy to invest in the hedge fund. This implies that the investor must be less risk averse than the manager to see a profit on the investment. Note that changing the $\gamma_{I}$ of the investor does not change the optimal allocation $\mathfrak{p}$ because the manager's risk-aversion parameter $\gamma$ remains unchanged.

We find that, if the investor's risk-aversion parameter is greater than some function, 


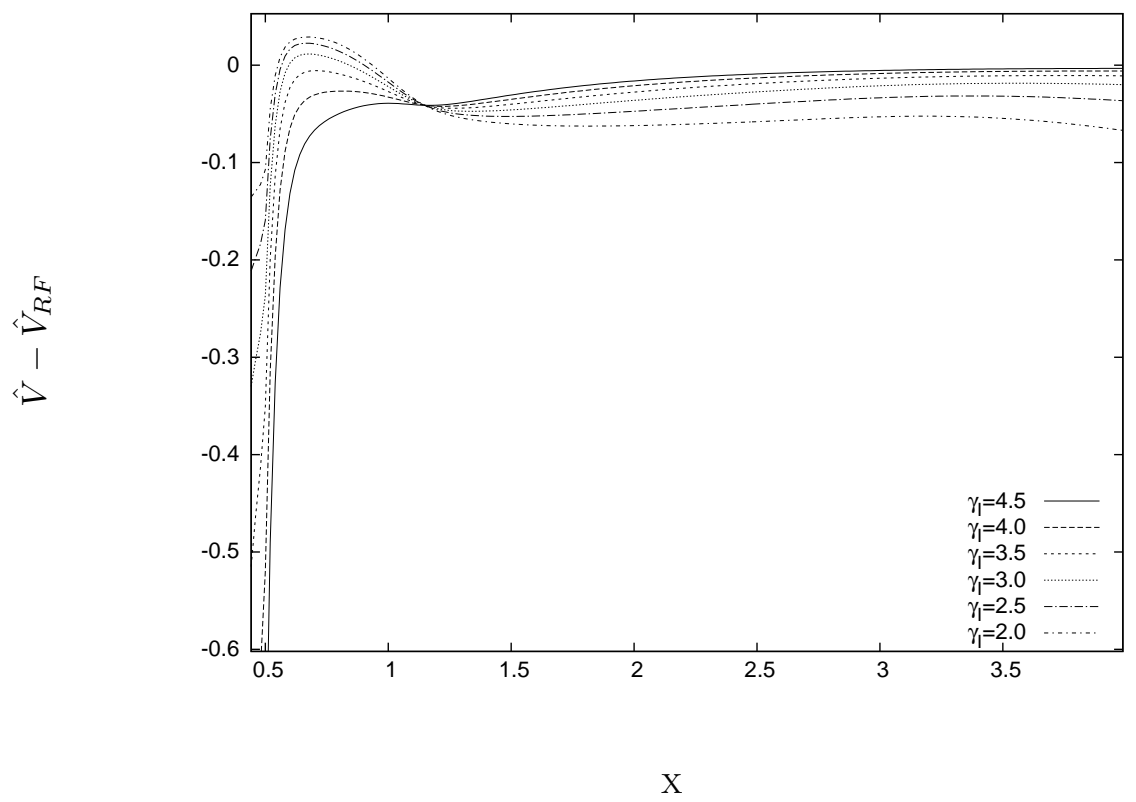

Figure 3: Plots of $\hat{V}-\hat{V}_{R F}$ functions, where we change the investor's risk-aversion parameter (i.e. $\gamma_{I}$ ), and we change the original parameters to $\mu=0.15$, and $\sigma=0.10735$. 
depending on the fund value $X$, the alpha generating strategy for the risky investment $\mu$ and the manager's risk-aversion parameter $\gamma$ (i.e. $\gamma_{I} \geq \phi(X, \mu, \gamma)$ ), the investor sees no profit, and if it is lower (i.e. $\left.\gamma_{I}<\phi(X, \mu, \gamma)\right)$ the investor sees profit, where the function $\phi(\cdot, \cdot, \cdot)$ is unknown. For better understanding of the effects of the expected rate of return $\mu$ and risk aversion parameter $\gamma_{I}$ on the investor's profit for different fund values, more examination of the function $\phi$ is needed, although ? gives some insight to this problem.

\section{Investor-Manager game}

In this section we deal with a new type of contract for a hedge fund, and the difference with the previous is that it adds the option for the investor to make an in/outflow $K_{t}$, at some pre-established time $t=t_{I}$, where $K_{\max }$ represents the amount of money available in the bank account at time $t_{I}$ to make the inflow, which could be invested in any proportion.

At time $t_{I}$, we propose a strategic game where the investor decides whether to move money, and how much, according to the decisions of the manager's allocation of the fund (i.e. proportions on risky and risk-less investment). As we described earlier, the model for manager and investor evolves through time and the strategic game is happening at a static time. Then we match the strategic game with the evolution of the wealth at a single and prescribed time, namely $t_{I}$.

Next, we explain the necessary extensions needed, to add the possibility of an in/outflow. First when an investor deposits or withdraws money from the fund, it has an effect on the high-water mark. For instance if the investor inflows money in the fund, then the manager must earn an incentive for this "new" investment. Moreover once the investor adds money to the fund, the manager must not perceive this as an extra income, and if the investor withdraws money, the manager should not take this as loss. Thus the value function changes in the sense that we now have two high-water marks and the manager earns incentives proportionally on the two high-water marks. If at the inflow time $t_{I}$ the investor decides to inflow $K$ we define a implicit new high-water mark $H_{K}=X_{t_{I}}+K$, with this implicit high-water mark we are able to calculate the proportions on which we are going to evaluate the incentive for the old high-water mark $H$ and the new high-water mark corresponding to the inflow $K$. In this way the payoff function for the manager changes to

$$
f\left(X, K, H_{K}\right)=a X+(1-a) b T X+(1-a) c\left(\left(\frac{H_{K}-K}{H_{K}} X-H\right)^{+}+\left(\frac{K}{H_{K}} X-K\right)^{+}\right) .
$$

Notice that at time $t_{I}$ there is an inflow of $K$, and to calculate the incentive at time $T$ we need to know the percentages of money invested $X_{t_{I}}$ at time $t_{I}$ and to keep track of this we add the extra dimension called $H_{K}$.

Note also that in this case any value of $K$ different from zero is going to imply a change in the percentage owned by the manager (recall that we use $a$ to represent this percentage), then $a$ is not longer a constant but a function depending on time and the value of the in/outflow $K$ (the time dependence of $K$ is avoided with the extra dimension $H_{K}$ ). This 
means that $a$ must be updated instantaneously and the owned portion changes to

$$
a\left(H_{K}, K\right)=a \frac{H_{K}-K}{H_{K}} .
$$

Thus the only changes for the setting of the manager (i.e. the value function $J$ ) are in the percentage $a\left(H_{K}, K\right)$ and the payoff function by changing $f\left(X_{T}\right)$ to $f\left(X_{t}, K, H_{K}\right)$.

For the investor, we have the same dynamics of the fund, but in this case he has extra money in the bank account to invest. So we model his wealth in two parts one is the money perceived from the fund $(\widehat{V})$ and the other is the money in the bank account $K_{\max }$ (for simplicity $K_{\max }$ is the amount of money in the bank account at time $t_{I}$ ), here the investor is able to make some inflows called $K_{t}$, since in our case is a single inflow we call it $K$. And the money in the bank account is described by

$$
\frac{d K}{d t}=K r, \quad \text { for } t \geq t_{I}
$$

As before, the changes reflected on the value function for the investor $\widehat{V}$ depend solely on the changes of the manager's payoff (i.e. $f\left(X_{t}, K, H_{K}\right)$ ). Then the total utility of wealth for the investor, adding the money in the bank account and making an inflow of $K$ at time $t_{I}$, gives us the following value function $\tilde{V}$ :

$$
\tilde{V}\left(t, X_{t}, H_{K}, K\right)=U_{I}\left(U_{I}^{-1}\left(\widehat{V}\left(t, X_{t}+K, H_{K}, K\right)\right)+\left(K_{\max }-K\right) e^{r\left(T-t_{I}\right)}\right) .
$$

Here we use the certainty equivalent of the wealth perceived in the fund. At the inflow time $t_{I}$, the investor seeks to maximise his wealth with possible inflows to the hedge fund that is

$$
V\left(t_{I}, X_{t_{I}}\right)=\max _{K \in\left[0, K_{\max }\right]} \tilde{V}\left(t_{I}, X_{t_{I}}, H_{K}=X_{t_{I}}+K, K\right) .
$$

\subsection{Investor-manager interaction}

In this subsection we describe the interaction between the manager and the investor at the single time $t_{I}$ when the in/outflow is made.

We model the interaction between the investor and the manager as a simple strategic game. In this game the players are the investor with actions related to the money movements in and out the fund and value function $V(t, X, K ; p)^{2}$, and the manager with actions related to portfolio allocations on the fund and value function $J(t, X+K ; p)$. Specifically the manager actions are the possible portfolio allocations represented by $p \in\left[0, p_{\max }\right]$ and the investor actions are the possible inflows or withdrawals represented by $K \in\left[K_{\min }, K_{\max }\right]$.

As a discrete approximation let us suppose that we have a finite range for $p$ and $K$. If we have $n$ possible allocations and $m$ possible money flows, we call $\Delta p=\frac{p_{\max }}{n}$, and $\Delta K=\frac{K_{\max }-K_{\min }}{m}$, in this manner for each integer $i$ between 0 and $n$ we represent the corresponding allocation by $p_{i}=i \Delta p$, similarly for each value $j$ between 0 and $m$

\footnotetext{
${ }^{2}$ To simplify the notation we avoid the variable $H_{K}$, which at time $t_{I}$ corresponds to $X_{t_{I}}+K$
} 


\begin{tabular}{|c|c|c|c|c|c|}
\hline & \multicolumn{4}{|c|}{ Investor } \\
\hline & & $K_{0}=K_{\min }$ & $K_{1}$ & $K_{2}$ & $\ldots$ \\
\hline & $p_{0}=0$ & $J_{0,0}, V_{0,0}$ & $J_{1,0}, V_{1,0}$ & $J_{2,0}, V_{2,0}$ & $\cdots$ \\
\hline & $p_{1}$ & $J_{0,1}, V_{0,1}$ & $J_{1,1}, V_{1,1}$ & $J_{2,1}, V_{2,1}$ & $\ldots$ \\
\hline & $p_{2}$ & $J_{0,2}, V_{0,2}$ & $J_{1,2}, V_{1,2}$ & $J_{2,2}, V_{2,2}$ & $\cdots$ \\
\hline & & $\vdots$ & $\cdot$ & $\cdot$ & \\
\hline
\end{tabular}

Table 3: Finite decisions example for the Investor vs Manager strategic game for a fixed fund value $X$. Where we use the notation $J_{i, j}=J\left(t_{I}, X+K_{i}, p_{j}\right)$ and $V_{i, j}=$ $V\left(t_{I}, X, K_{i}, p_{j}\right)$.

we represent the money flow by $K_{j}=K_{\min }+j \Delta K$. Hence the possible actions for the manager and investor in the strategic game are now integer values.

In this game the manager seeks for the allocation $\left(p_{i}, i \in\{0,1, \ldots, n\}\right)$ that makes his value function $J$ be maximum, and the investor looks for the amount of money to move into or out the fund $\left(K_{j}, j \in\{0, \ldots, m\}\right)$ that makes his value function $V$ to be as high as possible, in table ?? we find a schematic view of the game.

We assume the players to be rational and to have complete knowledge of the problem at the inflow time $t_{I}$ (i.e. at $t_{I}$ they know manager and investor value functions, actions and preferences), then we look at the Nash equilibrium point(s). One of the techniques to search for the Nash equilibrium is the best response function, that is for the investor we have

$$
\mathcal{B}_{I}\left(p_{i}\right)=\left\{K_{j}: V\left(t_{I}, X, K_{j}, p_{i}\right) \geq V\left(t_{I}, X, K_{l}, p_{i}\right), \text { for } K_{j}, K_{l} \in\left[K_{\min }, K_{\max }\right]\right\}
$$

and for the manager

$$
\mathcal{B}_{M}\left(K_{j}\right)=\left\{p_{i}: J\left(t_{I}, X+K_{j}, p_{i}\right) \geq J\left(t_{I}, X+K_{j}, p_{l}\right), \text { for } p_{i}, p_{l} \in\left[0, p_{\text {max }}\right]\right\}
$$

In words $\mathcal{B}_{I}\left(p_{i}\right)$ is the optimal amount that an investor has to move into the fund to get the highest value function given that the manager chooses to allocate $p_{i}$ in the risky investment, and $\mathcal{B}_{M}\left(K_{j}\right)$ is the optimal allocation that the manager must choose to get the most payment, given that the investor chooses to move $K_{j}$ into the fund. note that in this setting the best response function and the optimal control problem for the manager agree (and we have already solved the control problem), although now we deal across different values of fund wealth, that is

$$
\mathcal{B}_{M}\left(K_{j}\right)=\underset{p}{\arg \max }\left\{J\left(t_{I}, X+K_{j}, p\right)\right\} .
$$

Equation (??) is very important because it let us reduce one dimension in the maximisation since now we do not have to calculate the manager's wealth for every $p$ choice but just for the optimal, although this optimal had to be calculated for each choice of $K$. That is, having an inflow of $K_{j}$ the best response $p_{j}^{*}$ is the same as the optimal control for the manager's value function with fund value $X+K_{j}$. Therefore, the maximisation over $K_{j}$ depends only on the best response of the manager. This is represented on table ??. 


\begin{tabular}{c|c|c|c|c}
\multicolumn{5}{|c}{ Investor } \\
& $K_{0}=K_{\min }$ & $K_{1}$ & $K_{2}$ & $\ldots$ \\
\hline$p_{i}^{*}$ & $J_{0,0^{*}}, V_{0,0^{*}}$ & $J_{1,1^{*}}, V_{1,1^{*}}$ & $J_{2,2^{*}}, V_{2,2^{*}}$ & $\ldots$ \\
\hline
\end{tabular}

Table 4: Finite decisions example of the Investor vs Manager strategic game for a fixed fund value $X$ with the best response function added. Where we use the notation $J_{i, j^{*}}=$ $J\left(t_{I}, X+K_{i}, p_{j}^{*}\right)$ and $V_{i, j^{*}}=V\left(t_{I}, X, K_{i}, p_{j}^{*}\right)$, and $p_{j}^{*}$ is the best response for the inflow $K_{j}$.

\subsection{Computational approximation}

In order to add the extra variables $H_{K}, K$ to our computational scheme we increase two dimensions, this means that at each time-step we solve the differential equation over a three dimensional grid $\left(X, H_{K}, K\right)$. At each inflow level, the fund value parameter $a$ and the inflow high-water mark $H_{K}$ have been set such that they reflect the inflow. We solve the backwards HJB equation up to the inflow time $t_{I}$, and then carry out with the decision process.

\subsubsection{Investor decision process}

Given the information in the three-dimensional $\operatorname{grid}^{3}$, we want to find the maximum value for the value function $V$ across the different inflow levels. Note that if we have a fund with $X_{t_{I}^{-}}$money before the inflow then after the inflow the value would be $X_{t_{I}^{+}}=X_{t_{I}}=$ $X_{t_{I}^{-}}+K$. The objective is to search for the point having the maximum value function $V$ across the different inflow levels (i.e. the $K_{j}$ 's), a graphical explanation can be found in figure ??. There are different ways to seek the point where the maximum is attained, and to calculate the value function at that point, but we stick with a quadratic maximum search.

We know that the maximum is taken over a diagonal line and that any point $(X, K)$ in the diagonal line obeys the equation $X-K=X_{0}$ (for fixed value $X_{0}$ ), we define, over the line, the one parameter function

$$
h_{X_{0}}(K)=V\left(t_{I}, X_{0}, K\right)=U\left(U^{-1}\left(\left.\widehat{V}\left(t_{I}, X_{0}+K\right)\right|_{H+K}+\left(K_{\max }-K\right) e^{r\left(T-t_{I}\right)}\right)\right) .
$$

and thus in this approach for each of the $K_{i}$ 's, we first interpolate between the $X_{i}$ points to obtain the value of the function at a point in the line $X-K=X_{0}$. For example in figure ?? to calculate the value function at the point $\left(X_{0}+K_{1}, K_{1}\right)$ we interpolate between the values of $\hat{V}\left(X_{1}, K_{1}\right)$ and $\hat{V}\left(X_{2}, K_{1}\right)$ (also notice that in this figure $\left(X_{0}+K_{2}, K_{2}\right)=$ $\left.\left(X_{3}, K_{2}\right)\right)$. Once the points on the diagonal line are calculated, we use quadratic maximum interpolation around the greatest of the interpolated values to obtain the optimal $K^{*}$, then calculate the $X^{*}$ and the value function at the point $\left(X^{*}, K^{*}\right)$. To calculate $\hat{V}\left(X^{*}, K^{*}\right)$ we use bi-cubic interpolation.

\footnotetext{
${ }^{3}$ To simplify notation we choose to make all calculations in this section with two dimensions $(X, K)$ instead of three. The extension to three dimensions is straightforward since $H_{K}$ is embedded in $\hat{V}$ through the manager's payoff $f$.
} 


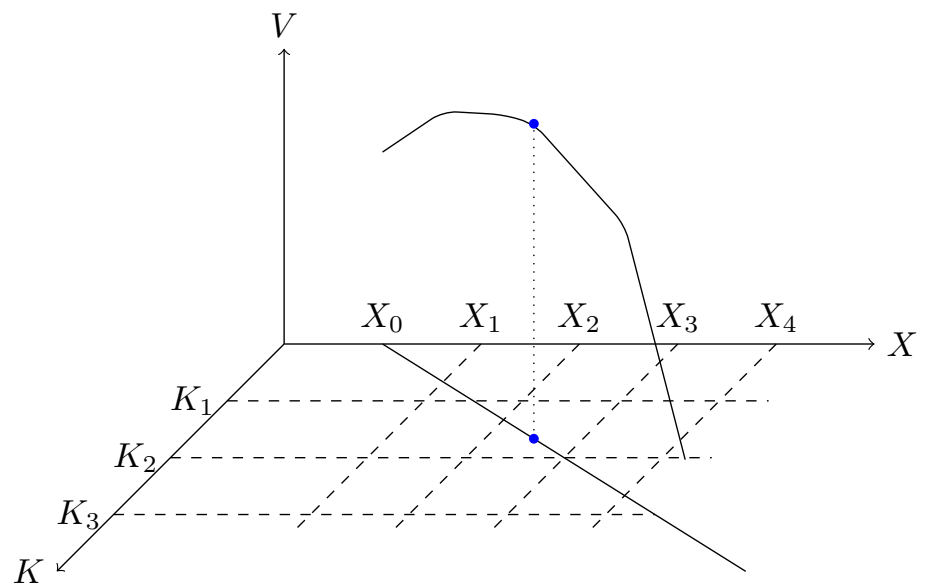

Figure 4: Example of the maximum point search of the game for the value fund value $X_{0}$, in the two dimensional grid, where the maximum point is represented as a blue dot.

Remark 4.1. If the level of $K$, such that the manager's utility of wealth reaches the maximum value, is below the actual $K_{i}$ implies inflowing money to get to the maximum value, and if the value is above implies outflowing money in order to get to the maximum. In this first case we are only concerned about inflows and in the outflow zone the investor does nothing. Also note that we must compare value function $V$ and not the hedge-fund value function $\hat{V}$. Therefore if we are at the point $\left(t_{I}, X, K\right)$, the value function for the money invested in the fund is $\hat{V}\left(t_{I}, X, K\right)$. and we search which inflow $\tilde{K}$ makes the most profitable strategy for the investor. We then maximize the function

$$
V\left(t_{I}, X, K\right)=\max _{\tilde{K} \in\left[K, K_{\max }\right]}\left\{U_{I}\left(U_{I}^{-1}\left(\hat{V}\left(t_{I}, X+(\tilde{K}-K), \tilde{K}\right)\right)+\left(K_{\max }-\tilde{K}\right) e^{r\left(T-t_{I}\right)}\right)\right\}
$$

In terms of the value function, this inflows act as jumps and induce discontinuities on the value function, then it causes fluctuation in our numerical scheme, so next we consider some changes in the computational technique to overcome this inconveniences.

\subsubsection{Importance of the $\theta$ scheme}

The money inflow generates a jump discontinuity on the value function and as is known that the Crank-Nicolson scheme, which we mostly use, does not behave as good as other schemes around discontinuities. The $\theta$ scheme, shown in ?, allows us to easily change between explicit, implicit, Crank-Nicolson schemes and let us have some schemes in between just by changing the value of the parameter (i.e $\theta=0$ for explicit, $\theta=0.5$ for Crank-Nicholson, and $\theta=1$ for implicit scheme).

After some experimentation changing the value of $\theta$ at $t_{I}^{-}$we found that the best response (in terms of smoothness of the value function) is given at $\theta=0$, which is the 


\begin{tabular}{c|c|c} 
& $\mu$ & $\sigma$ \\
\hline Low rate & 0.0778 & 0.05 \\
Medium rate & 0.15 & 0.10735 \\
High rate & 0.25 & 0.155
\end{tabular}

Table 5: Parameter change set for the hedge fund contract with the option to inflow.

explicit scheme, although it does not give a perfectly smooth solution, reason why we also divide the inflow in small parts next.

\subsubsection{Dividing the inflow in sub-steps}

A way to smooth the value function and its derivatives in the presence of a jump (inflow), is to divide the investor's inflow $K$ in $n$ smaller inflows $\frac{K}{n}$, which are executed in consecutive periods of time.

At the time of inflow $t_{I}$, instead of inflowing the whole amount $K$ and continue with one step of the finite difference scheme of size $\Delta t$, just before the inflow, we divide both inflow and time step in $n$ sub-steps, so we think of inflowing money from $t_{I}-\Delta t$ to $t_{I}$, in $n$ steps. Therefore we make small inflows of the same size $\frac{K}{n}$ to get to the total inflow $K$ and step through the finite difference scheme with time steps of size $\frac{\Delta t}{n}$.

This technique smoothens our value function, so next we show some results. Regard that the game is intended to investigate a new type of contract where the investor has the option to invest more in the fund (at time $t_{I}$ ), and under what circumstances he is willing to inflow money to the fund.

\section{$5 \quad$ Results}

Let us start by showing some comparisons of the inflow made by the investor at time $t_{I}=$ $\frac{1}{2} T$, where we change the expected rate of return of the risky asset $\mu$ (and correspondingly $\sigma)$, to check the effect it has on our model. The parameters are changing with respect to table ??, and we name the risky investment expected returns as low rate, medium rate and high rate. All other parameter are set as before and we let the inflow $K \in[0,0.3]$ (i.e. $K_{\min }=0$ and $K_{\max }=0.3$ ).

In figure ?? we show the optimal inflow decisions made by the investor $K^{*}$ as a function of the fund's wealth $X$, for our three different $\mu$ 's in table ??. It is clear, form the graph, that the inflow zone lies primarily between $\Phi$ and $H$, but notice that with a high rate of return there is a section around $[1.4,2.1]$ where the investor is again willing to inflow some money, and this effect increases with $\mu$. Figure ?? shows that even with a low rate of return (that is 0.02 higher than the riskless rate of return $r$ ), an investor having money in the hedge fund is willing to invest more (at about the segment $[0.55,0.75]$ ), even if he is not perceiving profit in the long term, as we examined before. Then, if the fund is in 


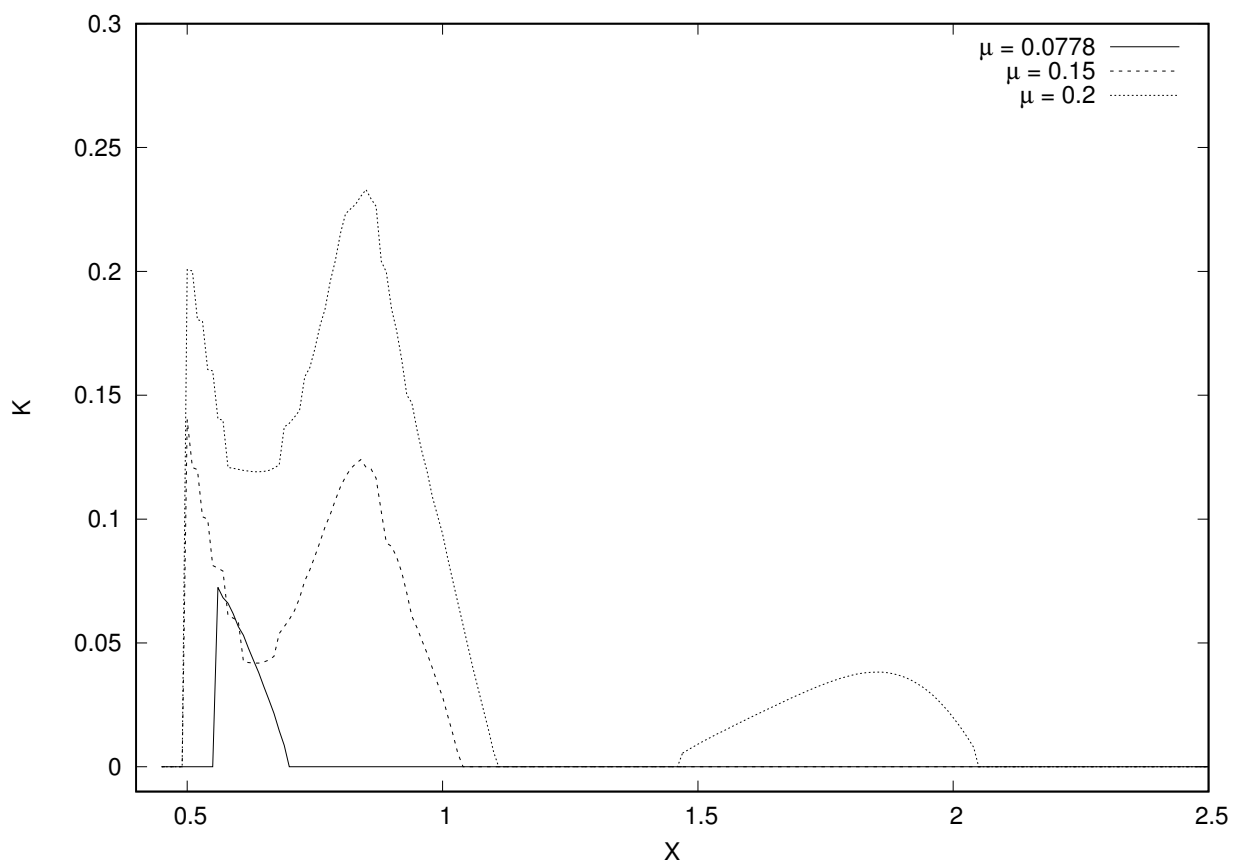

Figure 5: Optimal investor's inflow as a function of the fund's wealth, $K^{*}(X)$, for the expected return parameters $\mu$ as in table ??

the appropriate region, approximately between $\Phi$ and $H$, the investor is willing to keep the fund open in hopes of higher return.

Next we plot the differences between the investor's value function where the contract allows an inflow and the investor's value function having a contract without the option to inflow. Thus in figure ?? we notice that for values just above closure there is a region where the investor perceives benefit, represented by the positive values, thus positive value for the option. After that the investor is not perceiving any profit in return for the option to inflow, thus negative values for the option. The reason to this is that the manager adopts riskier strategies to get the inflow and hence creating a reverse effect on the investor view.

In figure ?? we overlapped the plots for the optimal inflow $K^{*}(X)$ and the difference of the value function corresponding to contracts with and without the inflow option. We appreciate that there is a region where the option is actually making the investor perceive profit but as the fund value grows closer to the high-water mark, we notice that the investor is also willing to inflow money, although at the end he perceives only losses (also because the manager will achieve the incentive fee), and this is what we call the reverse effect. Because the investor at time $t_{I}=\frac{1}{2} T$ perceives a benefit which is washed out as time passes and end up in loss.

Next we present some results about the manager's change of strategy, which helps to explain the reason for the reverse effect of the option (i.e. negative values) when having a contract with the option to inflow. If the manager knows that the investor is considering 


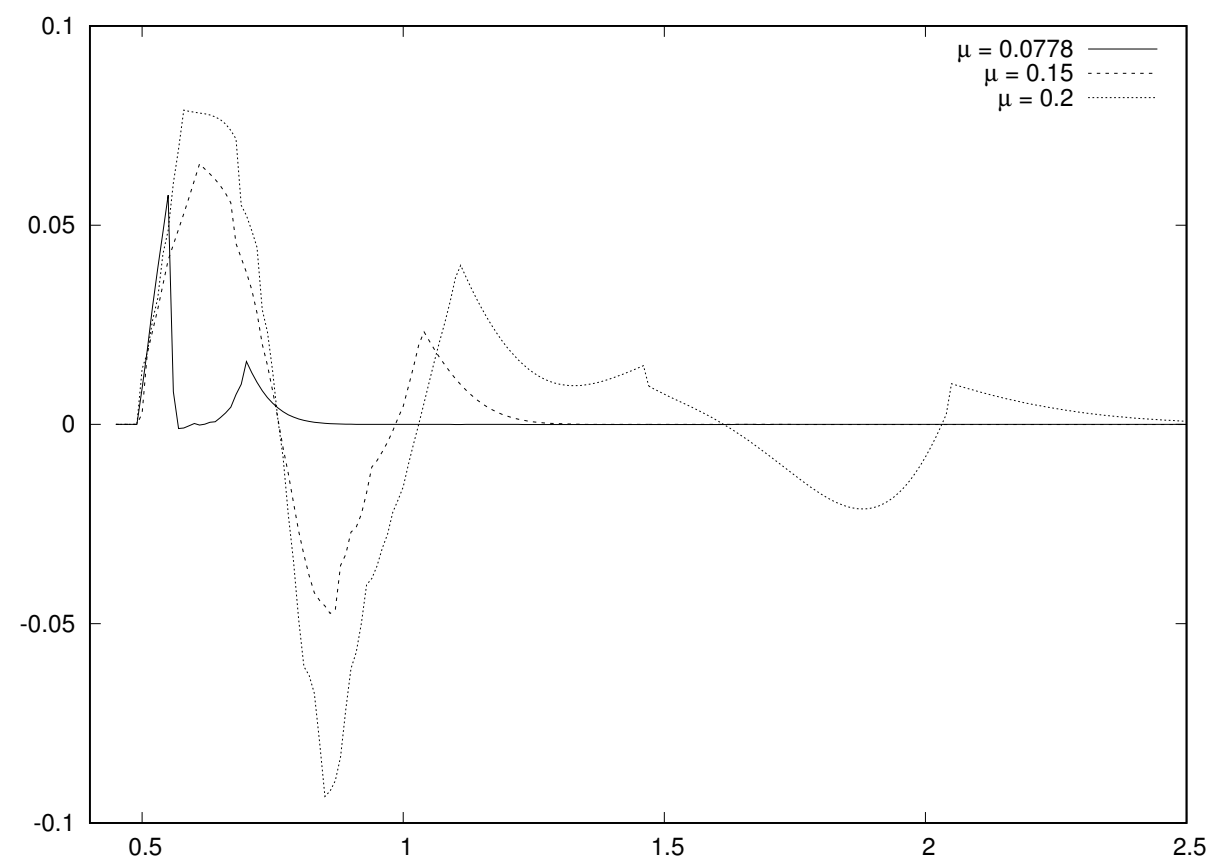

Figure 6: Difference of the value functions with the option inflow and with no option to inflow, i.e. $V(0, X, K)-V(0, X, K=0)$, using the expected return parameters $\mu$ as in table ?? 


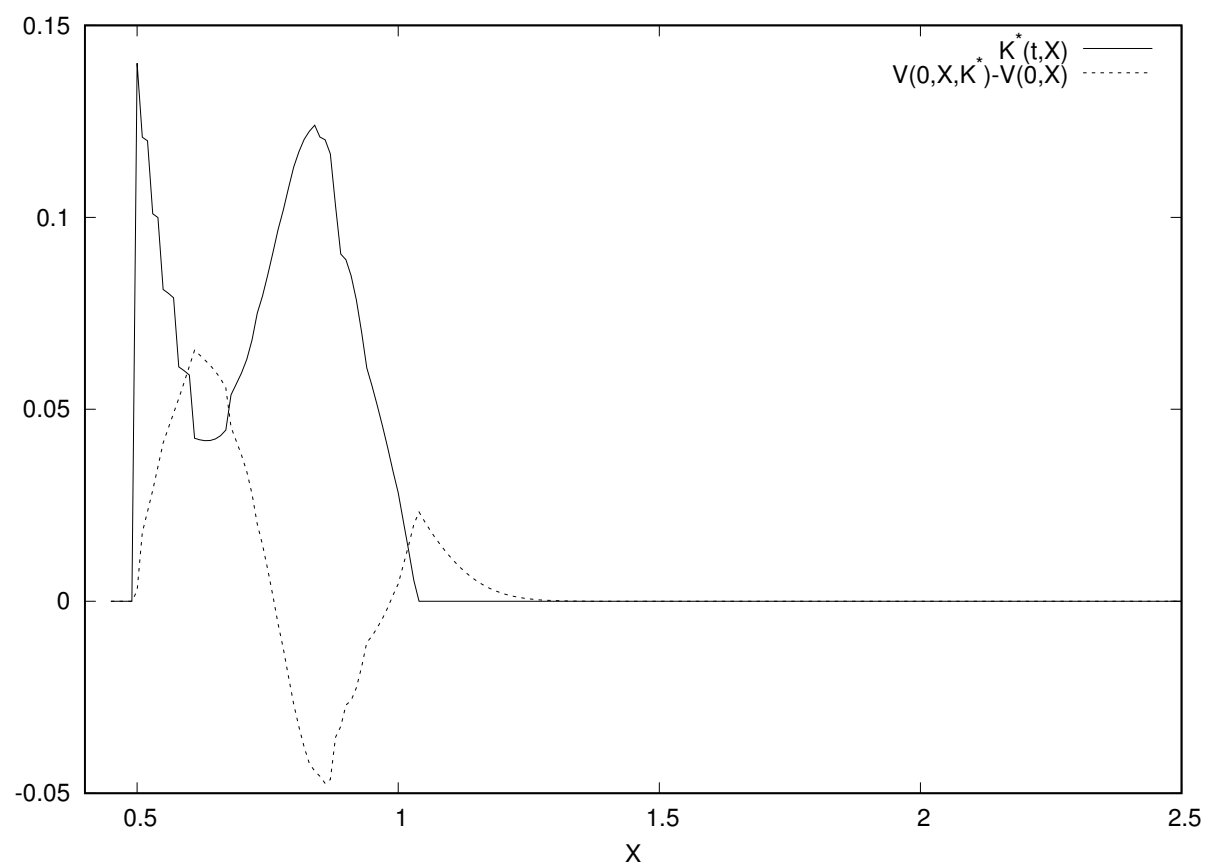

Figure 7: Graphs of the optimal inflow and difference of value functions $V(0, X, K)-$ $V(0, X, K=0)$ for $\mu=0.15$, where we can see clearly the reverse effect. 


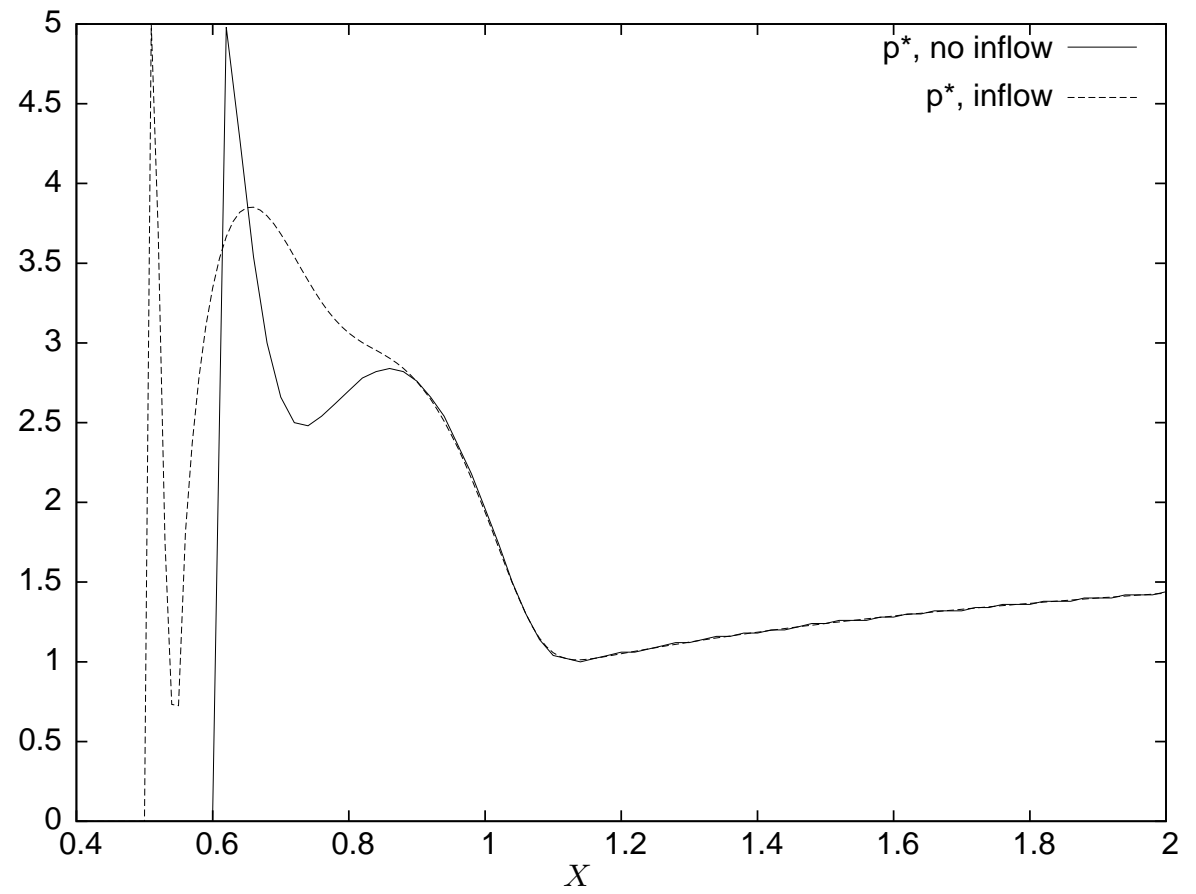

Figure 8: Optimal manager's allocation $p^{*}$ with inflow option and without inflow option, where the expected return is the usual (i.e. $\mu=0.0778$ ).

whether to inflow more money in the fund, his investment strategy changes because of the new opportunity, then the manager loses interest in the outside opportunity (endogenous closure) and he prefers to keep the fund open as we see in figure ??, where values close to $\Phi$ have a very high optimal allocation.

Figure ?? also shows that there is a region where the manager is betting that the fund gives more reward (for $0.5 \leq X \leq 0.55$ ) than the outside opportunity, as the manager risks to get the inflow and keep the fund open. In the multiperiod (or multiple years) setting since the (single) inflow is farther away it reduces its effect on the decisions made by the manager and hence this result fades away.

We end this subsection by exploring the consequences of letting the investor decide whether he wants to inflow or outflow money, this is done simply by letting the inflow $K \in\left[K_{\min }, K_{\max }\right]$ where $K_{\min }<0$. We made this change, with the usual parameters, and solve the inflow and outflow problem. Thus figure ?? shows the comparison of the investor's decision between letting only inflow (i.e. $K \in[0,0.15]$ ) and letting inflow and outflow (i.e. $K \in[-0.15,0.15]$ ), and we appreciate that the values where the investor is willing to add money to the fund does not change much, albeit a small zone near the closure region where the investor chooses to withdraw money and close the fund prematurely. For the medium and high rates, the inflow region does not change at all. All other regions, where the fund is open and there is no inflow, the investor now prefers to withdraw 


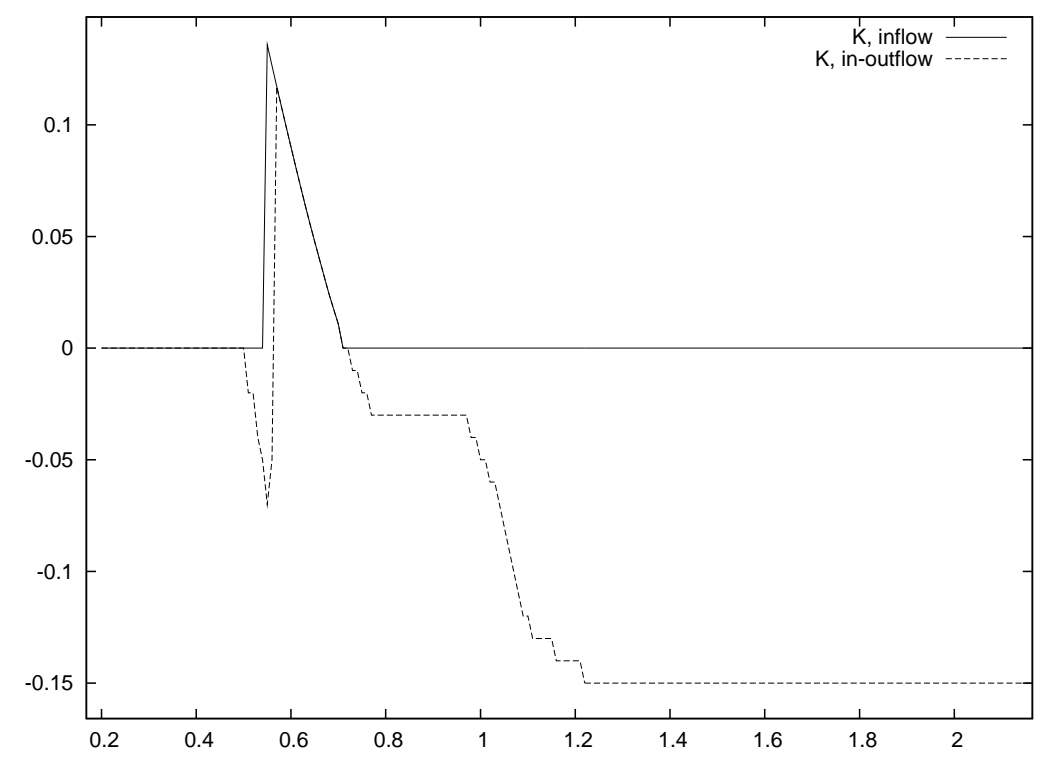

Figure 9: Comparison between the optimal inflow decision, and the optimal decision allowing inflows and outflows. For the parameter $\mu=0.0778$.

(outflow) money from the fund. This is expected because a rational behaviour for the investor is: if he sees profit he inflows money, and if he does not sees profit he outflows money.

\section{Conclusions}

Inspired by ? in section ?? we develop a PDE based model for a manager of a hedge fund, which includes: an European put option for the incentive fee, an American option to model an endogenous opportunity to close the fund, and a look-back option for the high-water mark reset each period end. Using viscosity solutions we prove that the problem has a unique solution and we propose a convergent robust numerical scheme.

Motivated by the work in ? among others, we extend our model to involve a hedge fund investor in section ??, and our model again gives rise to a PDE via the Feynman-Kac formula, we found that incentives and managerial fees are very high and as a consequence the investor is not perceiving profit because the return of the fund does not compensate the manager's payment. The expected return of the risky investment should exceed the $20 \%$ per annum to compensate this management fees, then to make the fund profitable for an investor, a new scheme of contract should be used. We also notice that the investor is perceiving profit in the more leveraged positions of the fund, suggesting that the investor prefers managers who behave riskier than himself.

This new an exiting results made us question: What is the rational reasoning behind investors? and why are they investing in hedge funds?. To answer this and some other 
questions in chapter ?? we propose a new type of contract which has an option to inflow money, and we model the decision to inflow as strategic game between the investor and the manager at the specific inflow time $t_{I}$. We found that an investor inflows (or deposits) money in the fund proportionally to the expected return of the risky asset, although this is not the only reason since even with low expected rate of return for the risky asset the investor inflows to keep the fund open (i.e. against a possible endogenous closure by the manager). We spot a reverse effect in the sense that even when the investor is not perceiving any profit on inflowing the money, he is willing to do it (comparing the contracts with and without the option to inflow). This is caused by a false expectation of higher results that get wiped down because of the change of strategy of the manager. We revise that managers change their allocation strategy just to gain the inflow, which is always beneficial for them.

We compare two types of contract in the first an investor signs a hedge fund and has to wait until terminal time to receive his money back, and in the second the investor has the same contract with the hedge fund, but in this case he has the option to inflow (or outflow) money at some pre-established time $t_{I}$. Comparing this two contracts we spot a behaviour that at first sight may be counter intuitive, and that corresponds to regions of negative values for the option, i.e. the reverse effect. Nevertheless after some more exploration we also find that this negative value of the option (saying that the investor is better in the contract without the option to inflow money) is due to changes in decisions of the manager. Therefore the fact that the option relates to changes in human behaviour makes the value of the option to be negative in some regions.

Then, we allow the investor to choose between inflow and outflow and spotted a rational behaviour because he maintains the inflows but in investments where he was choosing not to inflow he starts out-flowing.

The computational techniques and moreover the combination of techniques showed in this paper is robust and advantageous when considering PDEs with jumps or lack of smoothness and may be helpful to other researchers.

Currently our model allows the investor to make only one inflow and in a single specified time, we think that a more realistic setting would be to permit multiple inflows (and not at a prescribed time), this is not an easy task because our investor's value function has to keep track of all previous inflows, and hence the dimensionality would increase very rapidly, making the problem non tractable.

Regarding the graphs showing the difference in value functions between having the option to inflow and not having the option, in section ??, we conclude that some collaboration could be done in the strategic game to obtain investment decisions that are always beneficial for both parts. Thus instead of searching for a Nash equilibrium we could start by searching for collaborative equilibriums and what positions of investment are more beneficial for both parts, then we could extend the game to partial information games as well, where not all the information is known by both players. Another approximation to make strategies beneficial for both manager and investor is to seek for fairer contract schemes than the established $2 / 20$ scheme, considering that throughout our work we found evidence suggesting this scheme is not the optimal contract for investors. 


\section{References}

G. Aivaliotis and J. Palczewski. Tutorial for viscosity solutions in optimal control of diffusions. Social Science Research Network, 2010. URL http://dx.doi.org/10.2139/ ssrn. 1582548.

A. Andricopoulos, M. Widdicks, P. Duck, and D. Newton. Universal option valuation using quadrature methods. Journal of Financial Economics, 67(3):447-471, 2003.

A. Ang and N. P. B. Bollen. Locked up by a lockup: Valuing liquidity as a real option. Financial Management, 39(3)(15937):1069-1096, 2010. doi: 10.3386/w15937. URL http://www . nber .org/papers/w15937.

G. O. Aragon. Share restrictions and asset pricing: Evidence from the hedge fund industry. Journal of Financial Economics, 83:33-58, 2007.

G. Barles and P.E. Souganidis. Convergence of approximation schemes for fully nonlinear second order equations. Asymptotic Analysis, 4(3):271-283, 1991. doi: 10.3233/ ASY-1991-4305.

Z. Chen and P. A. Forsyth. A semi-lagrangian approach for natural gas storage valuation and optimal operation. SIAM Journal on Scientific Computing, 30(1):339-368, 2008. doi: 10.1137/060672911. URL http://dx.doi.org/10.1137/060672911.

M. G. Crandall, H. Ishii, and P. Lions. User's guide to viscosity solutions of second order partial differential equations. Bulletin of the American Mathematical Society, 27(1): $1-67,1992$.

W. H. Fleming and H.M. Soner. Controlled Markov Processes and Viscosity Solutions, volume 25 of Stochastic Modelling and Applied Probability. Springer, New York, 2006.

W. Fung, D. A. Hsieh, N. Y. Naik, and T. Ramadorai. Hedge funds: Performance, risk, and capital formation. The Journal of Finance, LXIII(4):1777-1803, 2008.

P. Guasoni and J. Obłój. The incentives of hedge fund fees and high-water marks. Mathematical Finance, 2013. ISSN 1467-9965. doi: 10.1111/mafi.12057. URL http: //dx.doi.org/10.1111/mafi.12057.

J. E. Hodder and J. C. Jackwerth. Incentive contracts and hedge fund management. Journal of Financial and Quantitative Analysis, 42:811-826, 2007.

Y. Huang, P. A. Forsyth, and G. Labahn. Combined fixed point and policy iteration for hamilton-jacobi-bellman equations in finance. SIAM Journal on Numerical Analysis, 50(4):1861-1882, 2012. doi: 10.1137/100812641. URL http://dx.doi.org/10.1137/ 100812641.

Y. Lan, N. Wang, and J. Yang. The economics of hedge funds. Journal of Financial Economics, 110:300-323, 2013.

R. C. Merton. Lifetime portfolio selection under uncertainty: The continuous-time case. The Review of Economics and Statistics, 51(2):247-257, 1969. 
H. Pham. Continuous-time Stochastic Control and Optimization with Financial Applications. Springer Berlin Heidelberg, Berlin, Heidelberg, 2009.

B. Ritholtz. Why investors love hedge funds. Bloomberg View, 2014. URL http://www . bloombergview.com/articles/2014-04-21/why-investors-love-hedge-funds.

G.D. Smith. Numerical Solution of Partial Differential Equations: Finite Difference Methods. Oxford : Clarendon Press, 2nd edition, 1978.

N. Touzi. Optimal Stochastic Control, Stochastic Target Problems, and backward SDE, volume 29 of Fields Institute Monographs. Springer, New York, 2013.

M. Tuchman. Warren Buffett on track to win hedge fund bet. Marketwatch, 2014. URL http://www.marketwatch.com/story/ warren-buffett-on-track-to-win-hedge-fund-bet-2014-12-04. 


\section{A Uniqueness of the solution}

The uniqueness of the viscosity solution is addressed in many related texts, such as ?, ?, ?, and ?. Where it is proved that the value function is a viscosity solution, but to verify that the solution is unique we must check the assumption 6.15. (pg. 76) in ? in order to utilise the comparison theorem (Theorem 6.17. in ?), then if we let

$$
\begin{aligned}
F\left(t, X, J, \frac{\partial J}{\partial t},\right. & \left.\frac{\partial J}{\partial X}, \frac{\partial^{2} J}{\partial X^{2}}\right) \\
& =\max \left\{-\frac{\partial J}{\partial t}-\max _{p}\left\{\frac{1}{2} \sigma^{2} p^{2} X^{2} \frac{\partial^{2} J}{\partial X^{2}}+((r+(\mu-r) p) X) \frac{\partial J}{\partial X}\right\}, G-J\right\}
\end{aligned}
$$

we have to check that:

1. There exists $\vartheta>0$ such that

$$
F(t, X, r, v, \vec{q}, \mathbf{A})-F\left(t, X, r^{\prime}, v, \vec{q}, \mathbf{A}\right) \geq \vartheta\left(r-r^{\prime}\right)
$$

For all $r \geq r^{\prime}$, and $(t, X, v, \vec{q}, \mathbf{A}) \in Q \times \mathbb{R} \times \mathbb{R}^{n} \times \mathcal{S}_{n}$.

Since in this case the function $F$ does not depend on $J(t, X)$ explicitly, a minor modification of the assumption is needed. According to ?, notice that for every $\epsilon>0$ and viscosity subsolution $\tilde{J}$ of (??), $\tilde{J}_{\epsilon}:=\tilde{J}+\epsilon t$ is also a subsolution of (??) since

$$
F\left(t, X, \tilde{J}_{\epsilon}, \frac{\partial \tilde{J}_{\epsilon}}{\partial t}, \frac{\partial \tilde{J}_{\epsilon}}{\partial X}, \frac{\partial^{2} \tilde{J}_{\epsilon}}{\partial X^{2}}\right) \leq-\epsilon<0 .
$$

Therefore, we obtain the result in (??) by choosing $\vartheta \leq \frac{1}{T}$ and using $\tilde{J}$ and $\tilde{J}_{\epsilon}$ since $\frac{\partial \tilde{J}_{\epsilon}}{\partial t}=\frac{\partial \tilde{J}}{\partial t}+\epsilon$.

This modification is enough for the comparison theorem since by letting $\underset{\sim}{J} \in L S C(Q)$ (lower semi-continuous envelope) and $\tilde{J} \in U S C(Q)$ (upper semi-continuous envelope), we have that $\tilde{J}_{\epsilon}-\underset{\sim}{J} \leq \sup _{\partial Q}\left\{\tilde{J}_{\epsilon}-\underset{\sim}{J}\right\}$ and $\tilde{J}-\underset{\sim}{J} \leq \sup _{\partial Q}\{\tilde{J}-\underset{\sim}{J}\}+\epsilon T$, which gives the comparison theorem as $\epsilon \rightarrow 0$.

2. There exists $\bar{w}: \mathbb{R}^{+} \rightarrow \mathbb{R}^{+}$with $\bar{w}\left(0^{+}\right)=0$, such that

$$
F(t, y, r, v, \alpha(x-y), \mathbf{B})-F(t, x, r, v, \alpha(x-y), \mathbf{A}) \leq \bar{w}\left(\alpha|x-y|^{2}+|x-y|\right) .
$$

For all $(t, x),(t, y) \in Q, r \in \mathbb{R}$ and $\mathbf{A}, \mathbf{B}$ such that

$$
-\left(\frac{1}{\epsilon}+|\alpha|\right) \mathbb{I}_{2} \leq\left(\begin{array}{cc}
\mathbf{A} & 0 \\
0 & -\mathbf{B}
\end{array}\right) \leq\left(\alpha+\epsilon|\alpha|^{2}\right)\left(\begin{array}{cc}
1 & -1 \\
-1 & 1
\end{array}\right) .
$$

Note that we have adapted the matrices to our case where the space dimension is 1 , and by letting $\alpha=\frac{1}{\epsilon}$ we obtain

$$
\left(\begin{array}{cc}
\mathbf{A} & 0 \\
0 & -\mathbf{B}
\end{array}\right) \leq 2 \alpha\left(\begin{array}{cc}
1 & -1 \\
-1 & 1
\end{array}\right)
$$


Since in equation (??) we take the maximum over a compact set, this maximum is attained in $\mathcal{A}=[0,4.5]$, denoted by $p^{*}$, and then

$$
\begin{aligned}
F(t, y, r, v, \alpha(x-y), \mathbf{B}) & -F(t, x, r, v, \alpha(x-y), \mathbf{A}) \\
& =\frac{1}{2} \sigma^{2} p^{* 2}\left(x^{2} \mathbf{A}-y^{2} \mathbf{B}\right)-\left(r+(\mu-r) p^{*}\right) \alpha(x-y)^{2},
\end{aligned}
$$

and by using the result in equation (??) we obtain

$$
\begin{aligned}
F(t, y, r, v, \alpha(x-y), \mathbf{B}) & -F(t, x, r, v, \alpha(x-y), \mathbf{A}) \\
& \leq \sigma^{2} p^{* 2} \alpha(x-y)^{2}-\left(r+(\mu-r) p^{*}\right) \alpha(x-y)^{2} \\
& =\left(\sigma^{2} p^{* 2}-\left(r+(\mu-r) p^{*}\right)\right) \alpha|x-y|^{2} .
\end{aligned}
$$

Then by letting $\bar{w}(z)=C z$, where $C>0$ is a constant greater than $\sigma^{2} p^{* 2}-(r+$ $\left.(\mu-r) p^{*}\right)$, we obtain the desired result in equation (??).

Since the assumption are verified, by the comparison theorem we know that the value function is the unique viscosity solution to the problem.

\section{B Non-smoothness of the value function}

For ensuring that the numerical method converges to the unique viscosity solution of the manager's problem posed in equation (??). We deal with three pasting (or troublesome) points: the first is at the exogenous closure (i.e. $\Phi=\frac{1}{2} H$ ), the second is the call option in the incentive fee, and the third is at the free boundary or endogenous closure. The difference between these three points is that, the first induces a discontinuity in the derivative of the value function $\frac{\partial J}{\partial X}(t, X)$ (since the condition is imposed at each time period), the second induces a discontinuity in the derivative of the payoff function $\frac{d U}{d X}(f(X))$, but not in the value function, and for the third we make a smooth pasting between the equations on the free boundary.

In the call option due to the incentive fee we assume that the payoff may not be smooth enough, but the value function is. That is, at the point $X=H$, the payoff function has a discontinuity in the first derivative because for values of the fund greater than $H$ the manager is winning the incentive fee (exercising the call option) while for values of the fund lower than $H$ is not, which means

$$
\begin{aligned}
& \frac{d U}{d X}\left(f\left(H^{-}\right)\right)=(a H+(1-a) b T H)^{-\gamma}(a+(1-a) b T) \\
& \left.\frac{d U}{d X}\left(f\left(H^{+}\right)\right)=(a H+(1-a) b T H)\right)^{-\gamma}(a+(1-a) b T+(1-a) c),
\end{aligned}
$$

but we assume that this discontinuity only lasts an infinitesimal fraction of time, so that immediately before the final time our value function $J\left(T^{-}, H\right)$ is assumed smooth. Notice that in this case the discontinuity only holds at the payoff, so that our value function, 
which is smooth in $[0, T)$, jumps instantly to the payoff at time $T$. This assumption enables us to use stochastic control techniques as usual, but with the special consideration at terminal time $T$.

On the other hand to manage the discontinuity in the derivative of the value function due to the exogenous closure, we follow ? and use the upwind differencing technique.

For this numerical method to converge to the unique viscosity solution we use ? conditions (i.e. stability, consistency and monotonicity).

The stability condition is $\left\|J^{m}\right\|_{\infty} \leq$ Const, which is straightforward since the value function of the numerical method is bounded by the Merton optimal portfolio condition (i.e. simplifying the problem to be similar to Merton's optimal allocation in ? and solving it). In other words the $m$ th numerical step is bounded by Merton's discount factor times the $(m+1)$ th step.

The consistency may be seen taking:

$$
\mathcal{D}(\Delta t, \Delta X, \varphi) \rightarrow F\left(t, X, \varphi, \frac{\partial \varphi}{\partial t}, D \varphi, D^{2} \varphi\right),
$$

where $\mathcal{D}(\Delta t, \Delta X, \varphi)$ denotes the discretised PDE applied to $\varphi$. In our case this is a consequence of the stochastic control for smooth functions by taking cases in the different regions $(X<\Phi$ and $X \geq \Phi$ ), thus the convergence is assured in both regions. Also notice that in the region $X \geq \Phi$ the convergence is due to the assumption of the smoothness at the point $X=H$.

The monotonicity of the HJB PDE is more difficult to explain, although we obtain the monotonicity result from the one-side derivatives, combined with ? solution, as we shall explain next.

Since at the exogenous closure we are imposing a discontinuity in the derivative of value function namely $\frac{\partial J}{\partial X}\left(t, \Phi^{-}\right) \neq \frac{\partial J}{\partial X}\left(t, \Phi^{+}\right)$, we cannot assume that $J$ is smooth and therefore we cannot apply stochastic control techniques, because the control becomes unbounded. Since our main interest is when the fund is open (taking the upper semicontinuous envelope as the optimal policy, as in ?), then we assume that the manager is solely influenced by the dynamics when the fund is open, so that when $X=\Phi$ we only take the derivative from the right side (as a consequence we control the portfolio from becoming unbounded). So that we calculate the one-side finite difference CrankNicolson approximation of order $O(\Delta X)$ to the HJB equation and the only change is for the PSOR method, in the case where $X=\Phi$. This treatment is called upstream or upwind differencing, and it suffices to keep the monotonicity of the scheme at the point $X=\Phi$, and gives the desired positiveness of the coefficients (following?) and all the values are originated from the region governed by the PDE.

Figure ?? shows some comparative graphs to exhibit the need for the upwind differencing (one-side derivative) on the exogenous closure boundary. For this purpose we show the optimal allocation $p^{*}$ (or optimal control) that the manager must follow in order to obtain the maximum expected utility of wealth. These graphs correspond to the case without endogenous closure because the effect of the upwind differencing is clearer. In this figure we show four graphs, on the left we use the normal SOR technique without the upwind differencing at the exogenous closure $X=\Phi$, and on the right we show the graphs with the upwind differencing (one-side derivative) at $X=\Phi$. The graphs on the top show 

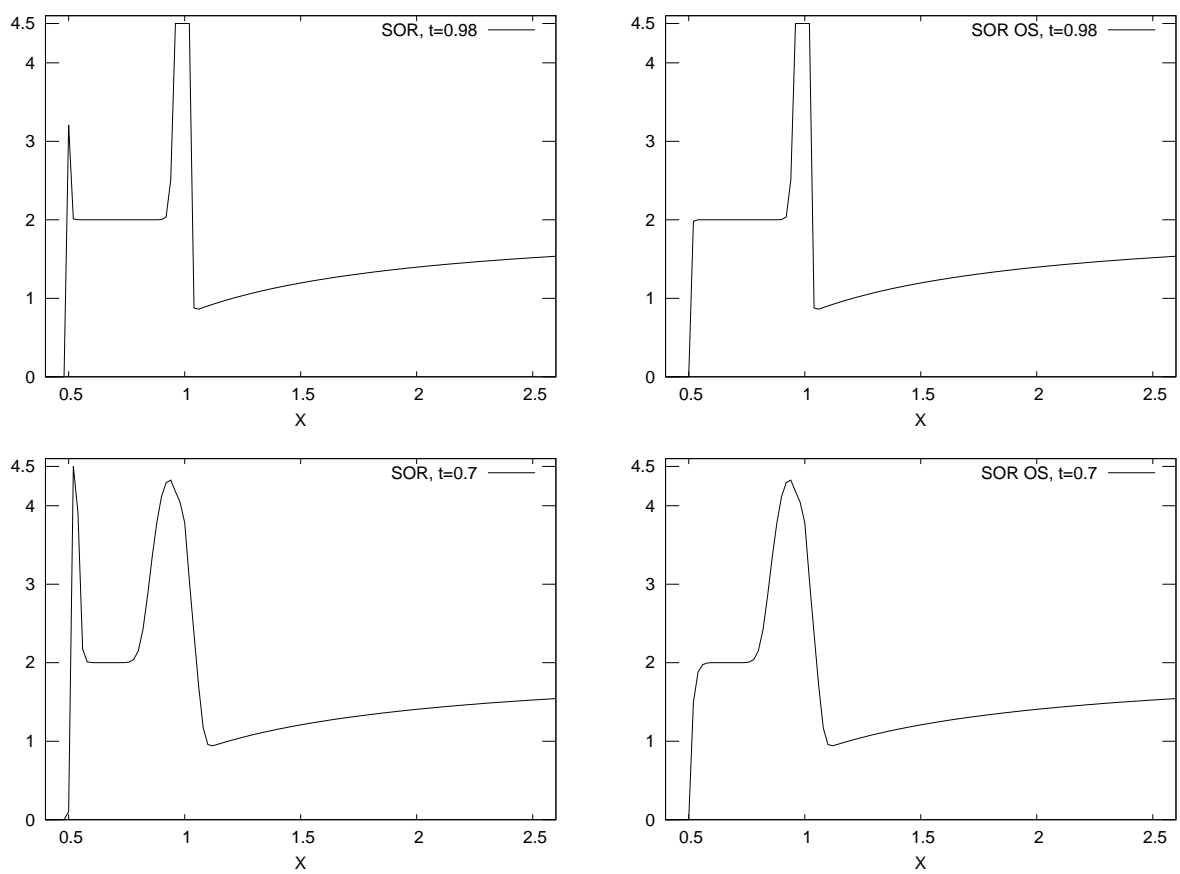

Figure 10: Comparison of the optimal manager allocation solutions $p^{*}(t, X)$ at time $t=$ 0.98 (top) and time $t=0.7$ (bottom). Using the Normal SOR technique (left), and the SOR with the upwind technique or One Side derivative (SOR OS) at the $\Phi$ boundary (right)

the effect of the upwind differencing after one time step $T-\Delta t$ (i.e. $t=0.98$ ), as the spike shown on the top-left graph, at $X=0.5=\Phi$ (due to the unboundedness of the control), is eliminated on the top-right graph.

Also in figure ?? at time $t=0.7$ (on the bottom), we see that the spike in the left graph grows as more steps are calculated, because the discontinuity effect persists. As $t \rightarrow 0$ the effect spreads and if we increase the range for $p$ it becomes unbounded. This illustrates the importance of the upwind differencing to ensure the monotonicity of the numerical method and hence convergence. 